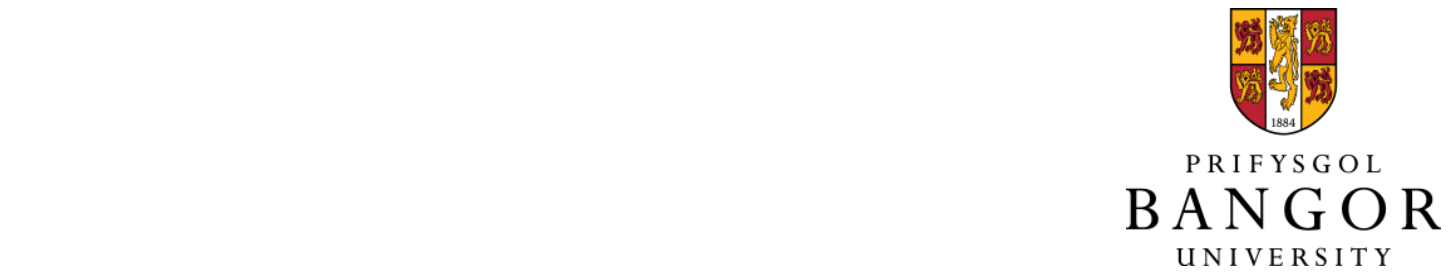

Brain potentials predict language selection before speech onset in bilinguals

Wu, Yan Jing; Thierry, Guillaume

\title{
Brain and Language
}

DOI:

10.1016/j.bandl.2017.04.002

Published: 01/08/2017

Peer reviewed version

Cyswllt i'r cyhoeddiad / Link to publication

Dyfyniad o'r fersiwn a gyhoeddwyd / Citation for published version (APA):

Wu, Y. J., \& Thierry, G. (2017). Brain potentials predict language selection before speech onset in bilinguals. Brain and Language, 171, 23-30. https://doi.org/10.1016/j.bandl.2017.04.002

\footnotetext{
Hawliau Cyffredinol / General rights

Copyright and moral rights for the publications made accessible in the public portal are retained by the authors and/or other copyright owners and it is a condition of accessing publications that users recognise and abide by the legal requirements associated with these rights.

- Users may download and print one copy of any publication from the public portal for the purpose of private study or research.

- You may not further distribute the material or use it for any profit-making activity or commercial gain

- You may freely distribute the URL identifying the publication in the public portal ?
}

Take down policy

If you believe that this document breaches copyright please contact us providing details, and we will remove access to the work immediately and investigate your claim. 


\section{Brain potentials predict language selection before speech onset in bilinguals}

Yan Jing $\mathrm{Wu}_{12}$ and Guillaume Thierry $\mathrm{y}_{3,4}$

1. College of Psychology and Sociology, ShenZhen University, 518060, China.

2. Department of Psychology, The University of Sheffield, S10 2TP, UK.

3. School of Psychology, Bangor University, LL57 2AS, UK.

4. Centre for Research on Bilingualism, Bangor University, LL57 2AS, UK.

Corresponding Author: Guillaume Thierry

Email: g.thierry@bangor.ac.uk

Address: School of Psychology, Bangor University, Bangor, North Wales, UK, LL57 2AS

\section{Abstract}

Studies of language production in bilinguals have seldom considered the fact that language selection likely involves proactive control. Here, we show that Chinese-English bilinguals actively inhibit the language not-to-be used before the onset of a picture to be named. Depending on the nature of a directive cue, participants named a subsequent picture in their native language, in their second language, or remained silent. The cue elicited a contingent negative variation of event-related brain potentials, greater in amplitude when the cue announced a naming trial as compared to when it announced a silent trial. In addition, the negativity was greater in amplitude when the picture was to be named in English than in Chinese, suggesting that preparation for speech in the second language requires more inhibition than preparation for speech in the native language. This result is the first direct neurophysiological evidence consistent with proactive inhibitory control in bilingual production.

Keywords: Bilingualism; speech production; event-related potentials; proactive inhibition; executive control. 


\section{Introduction}

Even when bilinguals function in one language, lexical representations of the other language are simultaneously active (Miwa et al., 2014; Morford et al., 2011; Thierry \& Wu, 2007; Wu \& Thierry, 2010). However, the cognitive mechanism that enables bilinguals to keep their languages functionally separate and operate in a seemingly monolingual fashion has not yet been elucidated. One hypothesis, the Inhibitory Control Model, poses that, in order to prevent cross-language interference, a control mechanism in the bilingual brain inhibits activation of non-target language representations allowing representations of the target language to reach the critical levels of activation required for speech production (Green, 1998). Evidence for such cross-language competition comes from picture-word interference studies in which bilinguals are generally asked to name a picture superimposed with a printed word. Indeed, when the word is semantically related to the picture but presented in a different language from that of the production language, naming latency is delayed (Costa \& Caramazza, 1999; Hermans et al., 1998). Also, when bilinguals switch between their two languages during a naming task, it takes longer to switch into their more dominant than into their less dominant language (Meuter \& Allport, 1999). Both sources of evidence suggest that lexical representations of the non-target language are actively inhibited to resolve competition between the two languages (as is the case in picture-word interference) or to deliver monolingual production in the target language (as is the case in language-switching).

Consistent with this hypothesis, functional neuroimaging studies of bilingual language production have repeatedly highlighted increased activation in left dorsolateral prefrontal cortex (DLPFC), anterior cingulate cortex (ACC), caudate nucleus, and bilateral supramarginal gyri (Abutalebi et al., 2008; Abutalebi \& Green, 2007; Crinion et al., 2006), that is, in brain regions critically involved in domaingeneral executive function such as response selection and inhibition (Aron, 2008; Grahn et al., 2008) and conflict monitoring (Botvinick et al., 2004).

In the same vein, event-related brain potential (ERP) studies have provided evidence in support of parallel lexical access during bilingual language production (Hoshino \& Thierry, 2011; Rodriguez-Fornells et al., 2005; Spalek et al., 2014; Wu \& Thierry, 2011) and inhibitory control (Kroll et al., 2008; Rodriguez-Fornells et al., 2006). Rodriguez-Fornells et al. (2005), for example, reported a negative-going ERP variation in fluent bilinguals performing a tacit naming task (i.e., judging whether a 
picture name begins with a vowel or a consonant), which the author interpreted as a correlate of the interference caused by the activation of the non-target language. The temporal characteristics and topography of this effect were comparable to that of the N200, a peak of ERPs classically modulated by executive control demands (Heil et al., 2000; Kopp et al., 1996) and associated with activation of the anterior cingulate cortex in relation to response suppression (Huster et al., 2010; Nieuwenhuis et al., 2003). These results are overall consistent with the hypothesis that language production in bilinguals involves the inhibition of unintended language representations via a cognitive control mechanism probably shared with generic executive control systems.

However, unlike reading and listening, speaking is primarily intentional and likely involves greater top-down control driven by conceptualization (i.e., the state of the semantic system) and proactive language selection (e.g., Strijkers et al., 2011; Strijkers \& Costa, 2016). In real life circumstances, bilinguals arguably select the language to speak on the basis of non-linguistic, contextual variables (e.g., the interlocutor's preferred language) and implement speech production in a goaloriented rather than a bottom-up fashion. Nevertheless, previous studies investigating the cognitive mechanisms underlying language production in bilinguals have mostly focused on linguistic or meta-linguistic tasks such as picture naming, language-switching, and translation (Runnqvist et al., 2011; Strijkers et al., 2013; Morales et al., 2015). Some of these studies have measured brain and / or behavioural responses after a stimulus is presented (e.g., Branzi et al., 2016; Hervais-Adelman et al., 2015), giving surprisingly little attention to the fact that the human brain not only functions reactively but also proactively and is indeed prone to prediction and anticipation (Federmeier \& Kutas, 1999; Martin et al., 2013; Strijkers, 2016).

In 2012, Luk et al. put forward the hypothesis that early activation in response to a cue may be sufficient to trigger proactive control in bilinguals. More recently, a few studies have reported evidence in support of multiple processing components being engaged, but the corresponding stage of processing and the mechanisms by which inhibition is applied to the non-target language remain to be defined (Branzi et al., 2014; Guo et al., 2011; Hanulová et al., 2011; Kroll et al., 2014; Misra et al., 2012; Mosca \& Clahsen, 2016; Van Assche et al., 2013; Strijkers et al., 2013; Strijkers and Costa, 2016). Nevertheless, such evidence has already been obtained in bilingual comprehension (Martin et al., 2016). 
It thus remains mostly unknown how bilingual speakers prepare for language production. In order to investigate this issue, here we examined pre-stimulus electrophysiological activity leading to real-time, overt speech production in bilinguals asked to name pictures. A group of late Chinese-English bilinguals named pictures in Chinese, English, or remain silent depending on the nature of a cue presented one second before the onset of each picture. ERP analysis was focused on the period of time between the onset of the visual cue and that of the stimulus picture. Following the presentation of the cue, we anticipated to observe a progressive negative shift of brain potentials indexing mental anticipation, the so-called contingent negative variation (CNV; (Jacobson \& Gans, 1981; Walter et al., 1964). If language production involves an inhibitory control mechanism that is generic and thus stimulusindependent, we should expect the CNV to index the relative intensity of the inhibition required to control the activation levels of the native and the second language, respectively. This is because, due to differences in proficiency and familiarity between the two languages, inhibiting native language representations likely requires greater processing resources (i.e., executive control) than inhibiting second language ones.

\section{Materials and methods}

\subsection{Participants}

Twenty (10 female) Chinese students from Bangor University, UK, aged between 18 and 23 years gave written consent to take part in the experiment that was approved by the ethics committee of Bangor University. They received financial compensation for their time. All participants were right-handed, had normal or corrected-to-normal vision, and reported no neurological problems or language impairments. All participants spoke Mandarin Chinese as their native language and knew no other language apart from English (i.e., they were late Chinese-English bilinguals). They started to learn English at the age of 12 (in secondary school) in a classroom context. Before coming to the UK, they had never stayed in an English-speaking country for any significant period of time. At the time of testing, they had lived in the UK for an average of $25( \pm 4.5)$ months and they were using English daily in both their private and academic lives. Their English proficiency, measured by the International English Language Testing System (IELTS)

(www.ielts.org/test_takers_information/what_is_ielts.aspx), was 6.5, which is the entrance requirement for most UK institutions as a non-native English student. The IELTS 
covers four fundamental language skills (i.e., reading, listening, writing, and speaking) and scores can vary between 0 and 9 .

\subsection{Stimuli}

One hundred pictures of common and highly imaginable objects were selected from the stimuli used in Wu and Thierry (2010). None of these pictures were semantically related or rhymed with another picture, either in Chinese or in English. They were controlled for basic visual characteristics such as size, contrast and resolution, and all pictures were presented on a white background. However, they were highly variable in terms of viewpoint, shape, and colour to minimise risk of a systematic bias due to inter-stimulus variance (Thierry et al., 2007). No cultural stereotype was featured to avoid a differential bias between Chinese and English naming (see examples in Fig. 1). No picture was repeated in the experiment.

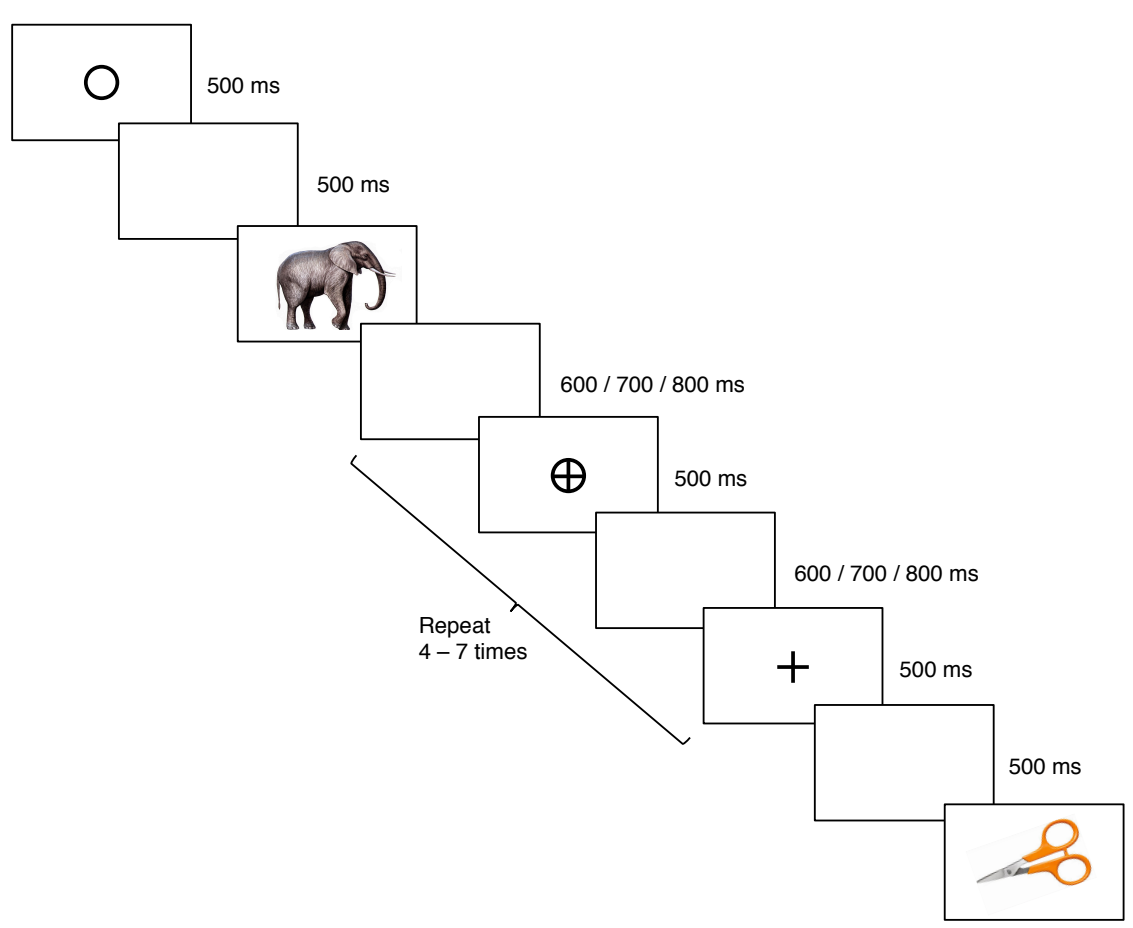

Figure 1. Experimental design and examples of stimuli.

\subsection{Procedure}

At the beginning of the experiment, verbal instruction was given to participants who sat on a chair about $100 \mathrm{~cm}$ away from a 19" CRT monitor in a sound-attenuated room with dimmed lighting. Each trial began with a cue presented in the centre of the screen for $500 \mathrm{~ms}$ followed by a blank screen for another $500 \mathrm{~ms}$. The visual cues 
were nonverbal symbols ('+', 'o', and ' $\Theta$ ') that have no specific ties to either of the languages of the participants. The cross and the circle each cued a particular language (English or Chinese), whilst the combined cue ' $\Theta$ ' indicated that no naming preparation was required (i.e., pictures were supressed to eliminate potential anticipation or planning of naming in one or the other language). The cue-language correspondence was counterbalanced between participants. Trial order was pseudorandomized and different from one participant to the next. In the naming trials, a picture was presented in the centre of the screen after the cue until the participant had named it. Participants were instructed to respond to the picture by naming it out loud in English or Chinese into a microphone connected with a voice key, which recorded voice reaction time (RT). An experimenter in the monitoring room manually recorded accuracy. The inter-trial interval was jittered between, 600, 700, and 800 ms. There were 100 naming trials, half in English and half in Chinese, and 550 nonnaming trials. Any two naming trials were separated by a sequence of 4, 5, 6, or 7 non-naming trials. The number of non-naming trials was pseudorandomly determined and the sequences were evenly distributed across the experiment. The purpose of this design was to trigger language selection by having bilingual participants name pictures in a dual-language context, while avoiding language switching by means of intervening non-naming trial series.

\subsection{ERP recording}

Electrophysiological data were recorded in reference to $\mathrm{Cz}$ at a rate of $1 \mathrm{kHz}$ from 64 $\mathrm{Ag} / \mathrm{AgCl}$ electrodes placed according to the extended 10-20 convention.

Impedances were kept $<5 \mathrm{k} \Omega$. Electroencephalogram activity was filtered on-line band pass between 0.1 and $200 \mathrm{~Hz}$ and refiltered off-line with a $25-\mathrm{Hz}$, low-pass, using a zero-phase shift digital filter. Eye blinks were mathematically corrected, and remaining artefacts were manually dismissed. There was a minimum of 30 valid epochs per condition in every subject. Four subjects were discarded from analysis due to insufficient ERP data quality. Epochs ranged from -100 to $1000 \mathrm{~ms}$ after the onset of the language cue, and from - 100 to only $550 \mathrm{~ms}$ after the onset of the picture to avoid speech contamination. Baseline correction was performed in reference to pre-stimulus activity, and individual averages were digitally rereferenced to the global average reference. ERP data were collected simultaneously to behavioural data. 


\subsection{ERP Data Analysis}

Due to the explorative nature of pre-stimulus ERP analysis, a temporal window for peak analysis was not determined at priori. The ERP data was first inspected by means of pairwise millisecond-by-millisecond comparisons between each of the English and Chinese conditions and the non-naming condition. We considered a difference as significant when differences were above threshold $(t>1.729, \mathrm{P}<0.05)$ for a continuous period of $>30$ ms (Guthrie \& Buchwald, 1991; Otten et al., 2006). The ERP waveforms elicited by the Chinese and the English naming cues showed a similar pattern against the non-naming cue: In both conditions, more negative-going amplitude was built up gradually following a naming cue as compared to a nonnaming cue, and the difference peaked at around $500 \mathrm{~ms}$ post cue onset. To quantify this difference, mean amplitudes were measured between 500-620 ms after cue onset over central scalp sites (linear derivation of FC1, Fz, FC2, C1, Cz, C2, $\mathrm{CP1}, \mathrm{CP} 2$, and $\mathrm{CPz}$ ) where mean amplitude differences were significant for both naming conditions vs. non-naming, and consistent with characteristics of the CNV (Hultin et al., 1996; Zappoli, 2003). After stimulus presentation, differences between language conditions were found in the classic N400 range (i.e., 350-500 ms) known to index naming difficulty (Schendan \& Kutas, 2007; Schendan \& Maher, 2009). Mean ERP amplitudes were subjected to a repeated measures analysis of variance (ANOVA) with cue type (English / Chinese / no naming) as the independent variable using a Greenhouse-Geisser correction where applicable. We also conducted a correlational analysis (Pearson correlation test) comparing the difference in mean CNV mean amplitude, N400 mean amplitudes, voice RT, and accuracy between English and Chinese naming conditions.

\section{Results}

\subsection{Behavioural results}

Picture naming accuracy was high both in Chinese, $M=97.7 \%, S D=2.2$, and in English, $M=95.1 \%, S D=3.0$ (Fig. 2A) and did not differ significantly between the two languages, $t(15)=1.77, P=0.97$. Voice RT latencies were however different between language conditions, $t(15)=3.94, P=0.001$, such that pictures were named significantly faster in Chinese, $M=914 \mathrm{~ms}, S D=262 \mathrm{~ms}$, than in English, $M$ $=981 \mathrm{~ms}, S D=293 \mathrm{~ms}$. 

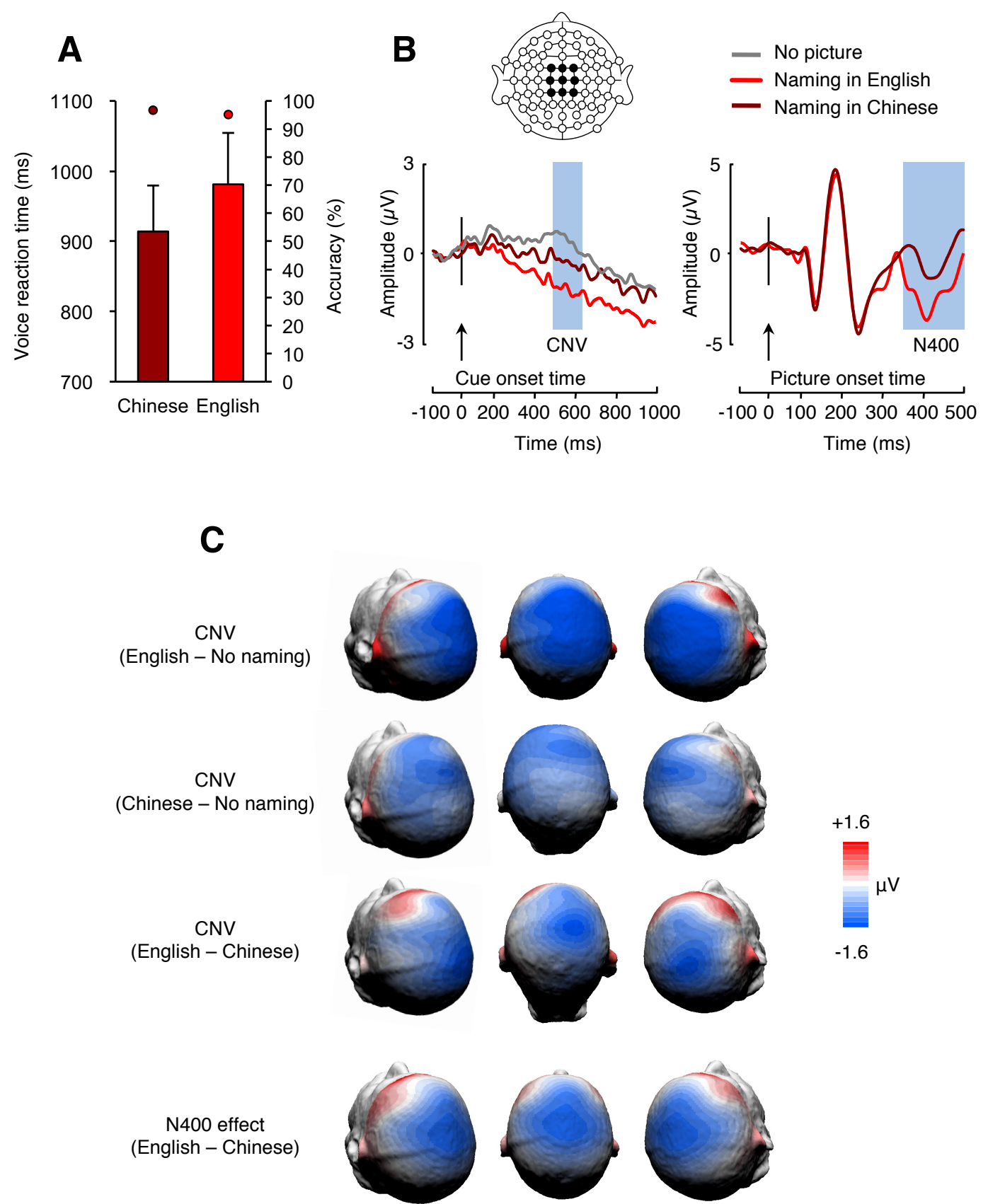

Figure 2. Behavioural and ERP results. (A) Naming reaction times (bars) and naming accuracy (dots) in Chinese and English; (B) Event-related potentials elicited by the language determination cue (left) and the subsequent picture stimulus (right). (C) Topographies of the CNV and N400 effects.

\subsection{ERP results}

A repeated measures ANOVA revealed a significant mean effect of cue type on the mean amplitude of the pre-stimulus CNV, $F(2,30)=15.17, P=0.001$ (Fig. 2B). Post hoc paired-samples t-test contrasts revealed that both the Chinese and the English cues elicited significantly more negative amplitudes than the non-naming cues, 
Chinese: $t(15)=2.259, P=0.039$, English: $t(15)=7.895, P<0.001$, two-tailed. Critically, mean CNV amplitude was also significantly more negative in the English than the Chinese cueing condition, $t(15)=2.649, P=0.018$, two-tailed. Pictures elicited a classic P1-N1-P2 complex followed by a negative deflection between 350$500 \mathrm{~ms}$ post stimulus onset. This N400 peak was significantly modulated between language cueing conditions, showing more negative amplitudes in the English than the Chinese condition, $t(15)=3.131, P=.007$, two-tailed (Fig. 2B\&C).

The correlational analysis (Pearson two-tailed) conducted on between-language differences (English-Chinese) of mean cue-elicited CNV amplitudes, mean pictureelicited N400 amplitude, and reaction times revealed a significant correlation between pre-stimulus CNV amplitude and voice RT, $r=-.516, \mathrm{n}=16, P=0.041$, and between pre-stimuli CNV amplitude and picture-elicited N400 amplitude, $r=0.525, \mathrm{n}$ $=16, P=0.037$, but not between picture-elicited N400 amplitude and voice RT, $r=-$ $.260, \mathrm{n}=16, P>0.1$ (Fig. 3).

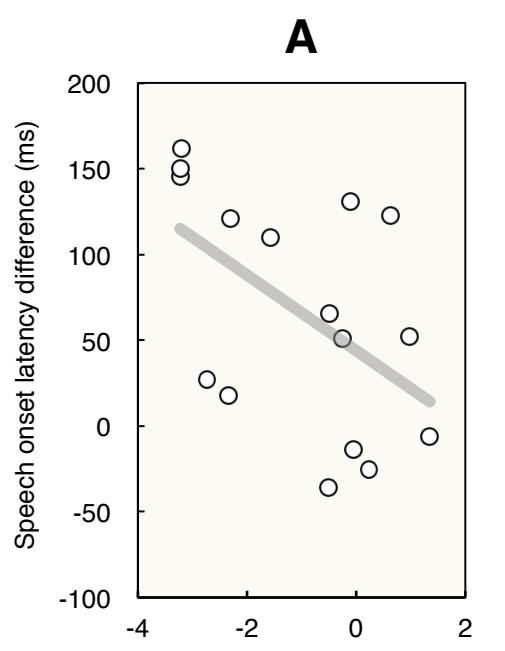

CNV mean amplitude difference $(\mu \mathrm{V})$

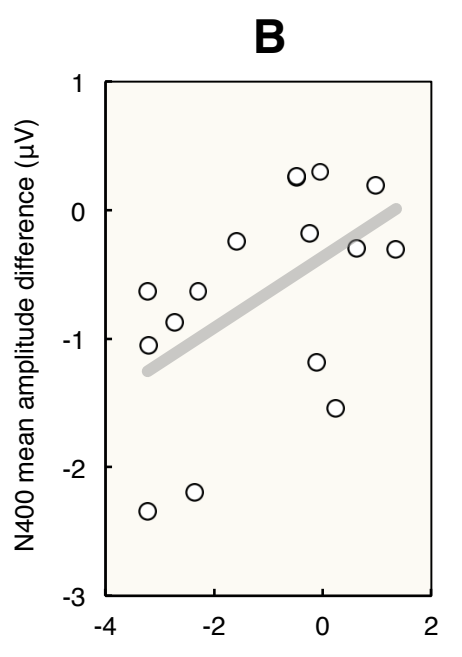

CNV mean amplitude difference $(\mu \mathrm{V})$

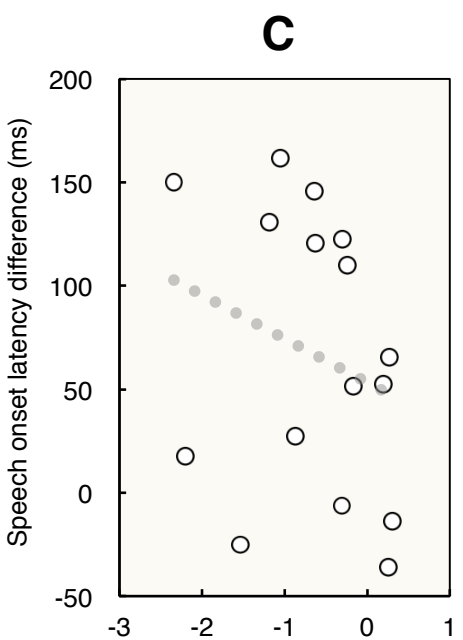

$\mathrm{N} 400$ mean amplitude difference $(\mu \mathrm{V})$

Figure 3. Results of between-language difference (Chinese - English) correlation analyses. (A)

Difference in voice RT as a function of the pre-stimulus CNV mean amplitude difference; (B)

Difference in picture-elicited N400 mean amplitude as a function of pre-stimulus CNV mean amplitude difference; (C) Difference in voice RT as a function of picture-elicited N400 mean amplitude difference.

\section{Discussion}

Previous research on bilingual control has provided limited insights into language inhibition mechanisms during production because it has mostly conflated correlates of language preparation with stimulus-specific activity. By examining brain potentials 
elicited by a preparation cue which was a simple shape counterbalanced between conditions, and before the presentation of a specific picture stimulus to be named, we were able to investigate how bilinguals prepare speech production in one of their languages. Behavioural results showed that Chinese-English bilinguals are faster naming pictures in their native language Chinese than their second language English, consistent with the difference in proficiency levels between languages. Furthermore, we found a significant ERP amplitude difference in pre-stimulus activity between the English and Chinese naming conditions: ERPs elicited by the Chinese and English naming cues both started to diverge significantly from baseline (no naming) at around $500 \mathrm{~ms}$ after cue onset, suggesting that cue processing had a comparable time-course between the two active naming conditions. The negative drift observed was consistent with the profile of the contingent negative variation (Tecce, 1972). From 500 ms to 620 ms, a larger CNV was observed when naming was required in English as compared to when it was anticipated in Chinese, suggesting that preparation for speaking in the second language elicits a greater CNV drift than preparation for speaking in the native language. Interestingly, correlational analyses indicated that differences in mean ERP amplitude and differences in naming latencies between first and second language naming were correlated, suggesting a functional relationship between pre-stimuli neural activities and speech production.

Previous studies have shown anticipatory neural mechanisms associated with learning (Galli et al., 2012), memory retrieval (Gruber \& Otten, 2010; Otten et al., 2006), and selective visual attention (Mazaheri et al., 2011), showing that brain activities preceding a cognitive event can influence, if not determine, the execution and outcome of the event. Speech production is a continuing process and, in bilingual speakers, language preparation is likely required in advance of the act of production itself. For example, the inhibitory control model posits 'language nodes' or 'language tags' as part of the conceptual system that facilitates language selection through top-down influences (Green, 1998). However, empirical evidence for the role that language nodes play in bilingual speech production has remained scarce because the majority of previous studies that have investigated language control have co-manipulated other variables (e.g., lexical-semantics, morphosyntax, phonology ( $\mathrm{Li}, 1998)$. To our knowledge, the current study is the first to demonstrate that pre-stimulus brain potentials can predict language selection in bilingual speech production. Since between-language differences in ERPs were observed in the absence of stimuli associated to specific linguistic representations, the most 
parsimonious explanation of our results is that of a relationship between pre-stimulus ERP amplitude and inhibitory control.

The finding of a correlation between CNV amplitude difference and speech onset latencies (Fig. 3A) suggests that proactive control, as indexed by pre-stimulus neural activities, might be the mechanism by which individual differences (e.g., second language proficiency) affect behavioural performance in bilinguals: Inhibitory control may have an impact not only throughout the chain of events leading to articulation but also semantic integration. Indeed, we found a correlation also between CNV amplitude difference and difference in N400 amplitude in the ERP elicited by the subsequent picture (Fig. 3B). In other words, the inhibitory impact of language selection appears to affect several -and possibly all- stages of language production and reveals subtle levels of interaction between language inhibitory control and semantic integration. As for the lack of a correlation between N400 amplitude difference and speech onset latencies (Fig. 3C), this was to be expected given the known remarkable disconnection between N400 amplitude and behavioural measurements of processing speed in language processing, especially when semantic evaluation is not critical for the task at hand (Heinze et al., 1998). The N400 is mostly an index of spreading of activation through the semantic system (Kiefer, 2002) and although it has a strong relationship with Cloze probability (DeLong et al., 2012) and semantic relatedness (Kutas \& Federmeier, 2011), it has little or no predictive value regarding the ensuing decision process or reaction times.

Based on a qualitative review of neuroimaging evidence, Abutalebi and Green (Abutalebi \& Green, 2008) proposed a neurocognitive model of bilingual language control, highlighting a network of brain regions considered critical in the implementation of three cognitive processes: (1) facilitating the selection of the appropriate language; (2) suppressing the irrelevant language; and (3) monitoring language use. However, the relatively low temporal resolution of neuroimaging methods (e.g., fMRI) prevents the recording of the fast neural dynamics underlying language processing. In a recent study, Reverberi et al., (2015) used a similar taskcuing paradigm to ours in order to separate neural mechanisms associated with proactive and reactive stages of naming. During the cuing stage, bilingual participants had to maintain the target language for as long as 8 seconds before generating a response, so as to accommodate the slow rate of evolution of the haemodynamic response recorded by fMRI. Such a delay between language preparation and execution likely induces task-irrelevant, superfluous activations. 
Indeed, their results failed to dissociate pre-stimuli activations in critical brain regions (e.g., ACC, left caudate, prefrontal cortex and inferior parietal lobule) that are involved in language control between the native and second language processing conditions. However, Blanco-Elorrieta \& Pylkkanen (2016) examined cue-directed language switches with magnetoencephalography (MEG), a neuroimaging technique that offers high temporal resolution (i.e., in terms of milliseconds), and showed recruitment of the dorsolateral prefrontal cortex (DLPC) beginning $400 \mathrm{~ms}$ after the presentation of a cue leading to an anticipated switch in production, but this was not observed in comprehension. In contrast with the results obtained by Reverberi et al. (2015), these findings suggest that bilinguals engage the DLPC when applying proactive control during language production by inhibiting the non-target language and raising the activation level of the target language at the same time.

The nature of neural preparatory processes in bilingual language control needs to be specified in the broader context of language activation and selection in general. As we have pointed out earlier, most studies on bilingual language production (and comprehension) have found that bilinguals activate both languages even when they operate in only one language (i.e., parallel language activation). These findings suggest that proactive control, as an instance of goal-directed behaviour, does not entirely filter out the irrelevant language by reducing its activation level prior to stimulus presentation. Thus, following the presentation of a stimulus, reactive language inhibition is also likely to be involved in order to implement speech planning. One account of this process is found in Strijkers et al. (2011; and 2015 for similar reasoning in comprehension): While a stimulus can proactively facilitate access to task/goal-relevant knowledge in general, proactive language control does not necessarily shut down automatic spreading activation between strongly connected lexical representations, because such mechanism is critically for cognitive processes such as categorisation. In the case of bilinguals, spreading activation would be language non-selective, thus preventing the irrelevant language from being completely "switched off". An alternative account is that proactive mechanisms enhance processing towards the relevant representations (in this case, the targetlanguage) through a facilitatory rather than an inhibitory process. As shown by some neuroscience evidence, proactive top-down processing can enhance target-relevant activation, which biases competition against the processes that are not in focus (e.g., Singer \& Gray, 1995; Engel et al., 2001; Egner \& Hirsch, 2005; Bar, 2007). The prestimulus activities we observed here may thus index neural responses reflecting an increase in the activation level of the target language, instead of reducing that of the 
non-target language. As a result, the non-target language would still be activated despite proactive control and the activation pattern would remain "traceable" when bilinguals perform a monolingual task. All things considered, it remains that, a proactive facilitatory account needs to be examined, for example, by recording variations of language activation levels before and after a bilingual speaker processes a cue.

In summary, the current study shows that brain potentials immediately preceding the presentation of a picture can dissociate naming in the first and the second language before a bilingual speaker knows what she has to say. Greater negative drifts of brain activity were found when participants prepared production in their second as compared to their first language, consistent with the Inhibitory Control Model (Green, 1998; Kroll et al., 2008), according to which 'language tags' participate in top-down control during bilingual language production. This being said other theoretical accounts involving, for example but not exclusively, facilitation via lowering of activation thresholds, provide equally plausible interpretational frameworks for the mechanisms underlying bilingual control (e.g., Strijkers and Costa, 2013; Strijkers, 2016). The correlation observed here between pre-stimulus neural activity and indices of language selection in bilinguals opens a novel perspective. For example, in the present study we only considered a mixed language context, that is when both languages are globally required and potentially called upon (Wu and Thierry, 2010). In order to mitigate for this, non-naming control trials were repeated so as to reduce immediate code-switching effects. Nevertheless, the context remained a mixed-language one. Furthermore, the pre-stimulus cues were presented with a fixed contingency and the picture stimuli were rather homogenous as regards the linguistic properties of their corresponding names (e.g., lexical frequency). Future studies will manipulate these factors to examine the role of language preparatory process in various contexts and shed light on the mechanisms of proactive control beyond the scope of the Inhibitory Control Model (e.g., the frequency lag hypothesis, Emmorey et al., 2013; Gollan et al., 2008). 


\section{Acknowledgements}

Yan Jing Wu is supported by the Beijing Normal University Open Grant. The authors would like to thank Marilyn Vihman and David Green for useful discussion. The authors declare no conflict of interest.

\section{References:}

Abutalebi, J., Annoni, J.M., Zimine, I., Pegna, A.J., Seghier, M.L., Lee-Jahnke, H., Lazeyras, F., Cappa, S.F., \& Khateb, A. (2008). Language control and lexical competition in bilinguals: an eventrelated FMRI study. Cerebral cortex, 18(7), 1496-1505.

Abutalebi, J., \& Green, D. (2007). Bilingual language production: The neurocognition of language representation and control. Journal of neurolinguistics, 20(3), 242-275.

Abutalebi, J., \& Green, D. (2008). Control mechanisms in bilingual language production: Neural evidence from language switching studies. Language and cognitive processes, 23(4), 557582.

Aron, A.R. (2008). Progress in Executive-Function Research From Tasks to Functions to Regions to Networks. Current directions in psychological science, 17(2), 124-129.

Bar, M. (2007). The proactive brain: using analogies and associations to generate predictions. Trends in cognitive sciences, 11(7), 280-289.

Blanco-Elorrieta, E., \& Pylkkänen, L. (2016). Bilingual language control in perception versus action: MEG reveals comprehension control mechanisms in anterior cingulate cortex and domaingeneral control of production in dorsolateral prefrontal cortex. Journal of neuroscience, 36(2), 290-301.

Botvinick, M.M., Cohen, J.D., \& Carter, C.S. (2004). Conflict monitoring and anterior cingulate cortex: an update. Trends in cognitive sciences, 8(12), 539-546.

Branzi, F.M., Della Rosa, P.A., Canini, M., Costa, A., \& Abutalebi, J. (2016). Language control in bilinguals: Monitoring and response selection. Cerebral cortex, 26(6), 2367-2380.

Branzi, F.M., Martin, C.D., Abutalebi, J., \& Costa, A. (2014). The after-effects of bilingual language production. Neuropsychologia, 52, 102-116.

Costa, A., \& Caramazza, A. (1999). Is lexical selection in bilingual speech production languagespecific? Further evidence from Spanish-English and English-Spanish bilinguals. Bilingualism: Language and Cognition, 2(03), 231-244.

Crinion, J., Turner, R., Grogan, A., Hanakawa, T., Noppeney, U., Devlin, J.T., Aso, T., Urayama, S., Fukuyama, H., Stockton, K., Usui, K., Green, D.W., \& Price, C.J. (2006). Language control in the bilingual brain. Science, 312(5779), 1537-1540.

DeLong, K.A., Groppe, D.M., Urbach, T.P., \& Kutas, M. (2012). Thinking ahead or not? Natural aging and anticipation during reading. Brain and language, 121(3), 226-239.

Egner, T., \& Hirsch, J. (2005). Cognitive control mechanisms resolve conflict through cortical amplification of task-relevant information. Nature neuroscience, 8(12), 1784-1790.

Emmorey, K., Petrich, J.A., \& Gollan, T.H. (2013). Bimodal bilingualism and the frequency-lag hypothesis. Journal of deaf studies and deaf education, 18(1), 1-11.

Engel, A. K., Fries, P., \& Singer, W. (2001). Dynamic predictions: oscillations and synchrony in topdown processing. Nature Reviews Neuroscience, 2(10), 704-716.

Federmeier, K.D., \& Kutas, M. (1999). A rose by any other name: Long-term memory structure and sentence processing. Journal of memory and language, 41(4), 469-495.

Galli, G., Leng Choy, T., \& Otten, L.J. (2012). Prestimulus brain activity predicts primacy in list learning. Cognitive neuroscience, 3(3-4), 160-167. 
Gollan, T.H., Montoya, R.I., Cera, C., \& Sandoval, T.C. (2008). More use almost always means a smaller frequency effect: Aging, bilingualism, and the weaker links hypothesis. Journal of memory and language, 58(3), 787-814.

Grahn, J.A., Parkinson, J.A., \& Owen, A.M. (2008). The cognitive functions of the caudate nucleus. Progress in neurobiology, 86(3), 141-155.

Green, D.W. (1998). Mental control of the bilingual lexico-semantic system. Bilingualism: Language and Cognition, 1(02), 67-81.

Gruber, M.J., \& Otten, L.J. (2010). Voluntary control over prestimulus activity related to encoding. The Journal of neuroscience, 30(29), 9793-9800.

Guo, T., Liu, H., Misra, M., \& Kroll, J.F. (2011). Local and global inhibition in bilingual word production: fMRI evidence from Chinese-English bilinguals. Neurolmage, 56(4), 2300-2309.

Guthrie, D., \& Buchwald, J.S. (1991). Significance testing of difference potentials. Psychophysiology, 28(2), 240-244.

Hanulová, J., Davidson, D.J., \& Indefrey, P. (2011). Where does the delay in L2 picture naming come from? Psycholinguistic and neurocognitive evidence on second language word production. Language and cognitive processes, 26(7), 902-934.

Heil, M., Osman, A., Wiegelmann, J., Rolke, B., \& Hennighausen, E. (2000). N200 in the Eriksen-task: Inhibitory executive process? Journal of psychophysiology, 14(4), 218.

Heinze, H.-J., Muente, T.-F., \& Kutas, M. (1998). Context effects in a category verification task as assessed by event-related brain potential (ERP) measures. Biological psychology, 47(2), 121135.

Hermans, D., Bongaerts, T., de Bot, K., \& Schreuder, R. (1998). Producing words in a foreign language: Can speakers prevent interference from their first language? Bilingualism: Language and Cognition, 1(3), 213-229.

Hervais-Adelman, A., Moser-Mercer, B., Michel, C.M., \& Golestani, N. (2015). fMRI of simultaneous interpretation reveals the neural basis of extreme language control. Cerebral cortex, 25(12), 4727-4739.

Hoshino, N., \& Thierry, G. (2011). Language selection in bilingual word production: electrophysiological evidence for cross-language competition. Brain research, 1371(100-109.

Hultin, L., Rossini, P., Romani, G., Högstedt, P., Tecchio, F., \& Pizzella, V. (1996). Neuromagnetic localization of the late component of the contingent negative variation. Electroencephalography and clinical neurophysiology, 98(6), 435-448.

Huster, R., Westerhausen, R., Pantev, C., \& Konrad, C. (2010). The role of the cingulate cortex as neural generator of the $\mathrm{N} 200$ and $\mathrm{P} 300$ in a tactile response inhibition task. Human brain mapping, 31(8), 1260-1271.

Jacobson, G.P., \& Gans, D.P. (1981). The contingent negative variation as an indicator of speech discrimination difficulty. Journal of speech and hearing research. Journal of speech and hearing research, 24(345-350

Kiefer, M. (2002). The N400 is modulated by unconsciously perceived masked words: Further evidence for an automatic spreading activation account of N400 priming effects. Cognitive brain research, 13(1), 27-39.

Kopp, B., Rist, F., \& Mattler, U. (1996). N200 in the flanker task as a neurobehavioral tool for investigating executive control. Psychophysiology, 33(3), 282-294.

Kroll, J.F., Bobb, S.C., Misra, M., \& Guo, T. (2008). Language selection in bilingual speech: evidence for inhibitory processes. Acta Psychology (Amst), 128(3), 416-430.

Kroll, J.F., Gollan, T., Goldrick, M., Ferreira, V., \& Miozzo, M. (2014). Speech planning in two languages: What bilinguals tell us about language production. The Oxford handbook of language production, 165-181.

Kutas, M., \& Federmeier, K.D. (2011). Thirty years and counting: Finding meaning in the N400 component of the event related brain potential (ERP). Annual review of psychology, 62, 621.

$\mathrm{Li}, \mathrm{P}$. (1998). Mental control, language tags, and language nodes in bilingual lexical processing. Bilingualism: Language and Cognition, 1(02), 92-93. 
Luk, G., Green, D. W., Abutalebi, J., \& Grady, C. (2012). Cognitive control for language switching in bilinguals: A quantitative meta-analysis of functional neuroimaging studies. Language and cognitive processes, 27(10), 1479-1488.

Martin, C., Thierry, G., Kuipers, J.-R., Boutonnet, B., Foucart, A., \& Costa, A. (2013). Bilinguals reading in their second language do not predict upcoming words as native readers do. Journal of memory and language, 69(4), 574-588.

Martin, C., Molnar, M., \& Carreiras, C. (2016). The proactive bilingual brain: Using interlocutor identity to generate predictions for language processing. Scientific report, 6: 26171.

Mazaheri, A., DiQuattro, N.E., Bengson, J., \& Geng, J.J. (2011). Pre-stimulus activity predicts the winner of top-down vs. bottom-up attentional selection. PloS one, 6(2), e16243.

Meuter, R.F., \& Allport, A. (1999). Bilingual language switching in naming: Asymmetrical costs of language selection. Journal of memory and language, 40(1), 25-40.

Misra, M., Guo, T., Bobb, S.C., \& Kroll, J.F. (2012). When bilinguals choose a single word to speak: Electrophysiological evidence for inhibition of the native language. Journal of memory and language, 67(1), 224-237.

Miwa, K., Dijkstra, T., Bolger, P., \& Baayen, R.H. (2014). Reading English with Japanese in mind: Effects of frequency, phonology, and meaning in different-script bilinguals. Bilingualism: Language and Cognition, 17(03), 445-463.

Morales, J., Yudes, C., Gómez-Ariza, C. J., \& Bajo, M. T. (2015). Bilingualism modulates dual mechanisms of cognitive control: Evidence from ERPs. Neuropsychologia, 66, 157-169.

Morford, J.P., Wilkinson, E., Villwock, A., Piñar, P., \& Kroll, J.F. (2011). When deaf signers read English: Do written words activate their sign translations? Cognition, 118(2), 286-292.

Mosca, M., \& Clahsen, H. (2016). Examining language switching in bilinguals: The role of preparation time. Bilingualism: Language and Cognition, 19(02), 415-424.

Nieuwenhuis, S., Yeung, N., van den Wildenberg, W., \& Ridderinkhof, K.R. (2003). Electrophysiological correlates of anterior cingulate function in a go/no-go task: effects of response conflict and trial type frequency. Cognitive Affective \& Behavioural Neuroscience, 3(1), 17-26.

Otten, L.J., Quayle, A.H., Akram, S., Ditewig, T.A., \& Rugg, M.D. (2006). Brain activity before an event predicts later recollection. Nature neuroscience, 9(4), 489-491.

Reverberi, C., Kuhlen, A., Abutalebi, J., Greulich, R.S., Costa, A., Seyed-Allaei, S., \& Haynes, J.-D. (2015). Language control in bilinguals: Intention to speak vs. execution of speech. Brain and language, 144, 1-9.

Rodriguez-Fornells, A., van der Lugt, A., Rotte, M., Britti, B., Heinze, H.J., \& Munte, T.F. (2005). Second language interferes with word production in fluent bilinguals: brain potential and functional imaging evidence. Journal Cognitive Neuroscience, 17(3), 422-433.

Rodriguez-Fornells, A., De Diego Balaguer, R., \& Münte, T.F. (2006). Executive control in bilingual language processing. Language Learning, 56(s1), 133-190.

Runnqvist, E., Strijkers, K., Sadat, J., \& Costa, A. (2011). On the temporal and functional origin of L2 disadvantages in speech production: A critical review. Frontiers in psychology, 2, 379.

Schendan, H.E., \& Kutas, M. (2007). Neurophysiological evidence for the time course of activation of global shape, part, and local contour representations during visual object categorization and memory. Journal of cognitive neuroscience, 19(5), 734-749.

Schendan, H.E., \& Maher, S.M. (2009). Object knowledge during entry-level categorization is activated and modified by implicit memory after $200 \mathrm{~ms}$. Neurolmage, 44(4), 1423-1438.

Spalek, K., Hoshino, N., Wu, Y.J., Damian, M., \& Thierry, G. (2014). Speaking two languages at once: Unconscious native word form access in second language production. Cognition, 133(1), 226231.

Singer, W., \& Gray, C. M. (1995). Visual feature integration and the temporal correlation hypothesis. Annual review of neuroscience, 18(1), 555-586. 
Strijkers, K., Holcomb, P.J., \& Costa, A. (2011). Conscious intention to speak proactively facilitates lexical access during overt object naming. Journal of memory and language, 65(4), 345-362.

Strijkers, K., Baus, C., Runnqvist, E., FitzPatrick, I., \& Costa, A. (2013). The temporal dynamics of first versus second language production. Brain and language, 127(1), 6-11.

Strijkers, K., Bertrand, D., \& Grainger, J. (2015). Seeing the same words differently: The time course of automaticity and top-down intention in reading. Journal of cognitive neuroscience, 27(8), 1542-1551.

Strijkers, K. (2016). A Neural Assembly-Based View on Word Production: The Bilingual Test Case. Language Learning, 66(S2), 92-131.

Strijkers, K., \& Costa, A. (2016). The cortical dynamics of speaking: Present shortcomings and future avenues. Language, cognition and neuroscience, 31(4), 484-503.

Tecce, J.J. (1972). Contingent negative variation (CNV) and psychological processes in man. Psychological bulletin, 77(2), 73.

Thierry, G., Martin, C.D., Downing, P., \& Pegna, A.J. (2007). Controlling for interstimulus perceptual variance abolishes N170 face selectivity. Nature neuroscience, 10(4), 505-511.

Thierry, G., \& Wu, Y.J. (2007). Brain potentials reveal unconscious translation during foreignlanguage comprehension. Proceedings of the National Academy of Sciences of the United States of America, 104(30), 12530-12535.

Van Assche, E., Duyck, W., \& Gollan, T.H. (2013). Whole-language and item-specific control in bilingual language production. Journal of Experimental Psychology: Learning, Memory, and Cognition, 39(6), 1781.

Walter, W.G., Cooper, R., Aldridge, V.J., McCallum, W.C., \& Winter, A.L. (1964). Contingent Negative Variation: an electric sign of sensorimotor association and expectancy in the human brain. Nature, 203, 380-384.

Wu, Y.J., \& Thierry, G. (2010). Chinese-English bilinguals reading English hear Chinese. Journal of Neuroscience, 30(22), 7646-7651.

$\mathrm{Wu}$, Y. J., \& Thierry, G. (2010). Investigating bilingual processing: the neglected role of language processing contexts. Frontiers in psychology, 1, 178.

Wu, Y.J., \& Thierry, G. (2011). Event-related brain potential investigation of preparation for speech production in late bilinguals. Frontiers in psychology, 2, 114.

Zappoli, R. (2003). Permanent or transitory effects on neurocognitive components of the CNV complex induced by brain dysfunctions, lesions and ablations in humans. International journal of psychophysiology, 48(2), 189-220. 